\title{
Universal Oneness as the Ulterior Motive of the Incarnation of
}

\author{
Radha and Krishna
}

Anjana V C

M.Phil. Research Scholar

Sree Narayana Guru College

K. K Chavadi

Coimbatore, Tamil Nadu, India

anjooschandran15@gmail.com

Ms. R. Kavitha

Asst. Professor, MA; M.Phil

Sree Narayana Guru College

K. K Chavadi

Coimbatore, Tamil Nadu, India

Abstract

My Affair with Radha, the debut work of Kunal Desai is the dedication to his readers who firmly believe in the divine couple Radha and Krishna. The intention of the author was to spread the awareness of the significance of divine love to the world through the example of Radha and Krishna who remain to be the epitome of transcendental oneness. The human life 


\section{https://doi.org/10.24113/ijellh.v7i11.10113}

that has been influenced in multiple ways throughout the life time, fails to overcome the temptations and eventually ends up in misery. A solution to all the misery in the world is to experience the feeling of oneness from within, which uplifts the individual from selfishness to selflessness and eventually the individual feels empathy towards all things. A world with such human beings with the feeling of oneness, will obviously be in harmony and without any miseries.

Keywords: Oneness, Empathy, Misery, Temptations, Epitome

The neonatal phase of the human life is the purest and the most marvellous that nobody could ever deny, as it remains completely selfless and highly sensitive. Gradually throughout the developmental stage, the human life is fed by the outside forces in all aspects that are physical, mental, emotional and intellectual. The flavours of differences discriminations knowledge about self and all the characteristics of human beings expands itself throughout the process of development until it becomes an adult. During the course of this development there is a drastic change in behavioural and attitudinal characteristics of the individual, that has turned itself from selflessness to selfishness and sensitivity to insensitiveness. This has become a common cycle of events in the development of human beings all over the world, resulting in today's society where a lot of people remain miserable.

Universal love or oneness is the ultimate and only solution to the miseries caused and faced by human beings. The differences in the world extends beyond caste, culture, religion, countries, colour, race and a lot more. The simplest form of difference is found between animals, humans and other things of ecosystem that sustains life on earth. Knowledge about the differences among the various things known to the human beings provides essential opportunities to safeguard them but on the other hand these same differences create a sense of domination over the others that are perceived to be inferior. It takes a lot more understanding 


\section{https://doi.org/10.24113/ijellh.v7i11.10113}

and experience to finally realise that differences are a sort of awareness about the similar nature of all things in this world and beyond.

Radha was the embodiment of a particular field of energy that expanded from Krishna, creating a difference between both of them in the physical aspects and connecting them together with a similarity which lies deeper within. The similarity that remained happened be love in its purest form untouched by any kind physical barriers. The only challenge that fell upon them was the curse to be separated from each other and also that Radha forgets about the love between them for hundred human years. This curse reminds a similar event of day to day life, where the mother and the offspring remains together and in complete oneness until childbirth and gradually as the child grows, the love and oneness felt at the mother's womb is forgotten, like Radha who forgets the love that she had for Krishna. The hundred years of the curse resembles the average life span of human beings on earth. The separation can also be related to the separation of man the microcosm from God or the macrocosm.

The experiences of the individual creates a memory within him, which remains stable and also gets transferred to the generations to come in the form of genetics. Thus an individual memory or experience transforms beyond the physical body, and if the individual expands his sense of self beyond all physical boundaries, a universal sense of oneness can be felt. If oneness is achieved there will not be any struggles, sufferings or violence in the world. Radha and Krishna are eternally together without being married, since a ritual alone could never guarantee love in its entirety. On the other hand the transcendental bliss that they experienced were beyond physicality and it sustained the same throughout ages and even many years after the end of their incarnation people still think about them in a singular form as Radha Krishna. 


\section{https://doi.org/10.24113/ijellh.v7i11.10113}

The importance of the feeling of oneness and universal brotherhood has been preached by several organisations and firms that works towards the single hearted goal of world peace. When this feeling is experienced with another person it is generally named as love, and when this experience expands drastically, it can be felt among the families and friends of the individuals. But mostly this experience stays within this circle and never expands beyond the community or culture. The aspect ratio of the experience must expand till the limits are not felt and the limitlessness of this divine oneness must be felt among each living beings in order to demolish all the violence in the world.

The human being with the experience of such a divine love within can never turn evil and cannot hurt anyone. The empathical value increases and thus there would be no necessity to initiate any plan or process for relieving the pain of others, since there will be harmony naturally restored. Throughout the living phase on earth Radha and Krishna proved their divine love, which is timeless, selfless and immortal. There was no boundaries to such a profound feeling of oneness, which is beyond all physical necessities and carnal temptations. "The happiness that can be secured by such absolute love cannot be obtained elsewhere"(26). They were cursed, separated and all other kinds of sufferings beheld them and still the oneness remained unchanged, and the same made them the epitome of transcendental oneness. Radha's love for Krishna was exhibited by the way she cared for each organism around her, as she felt a oneness with Krishna and that she could easily realise that all things were his manifestations. Thus they proved the world that love of the ulterior nature is the real expression of oneness that is felt from within towards all things.

In the present times, all over the world there is a drastic increase in the crime rates that gives rise to protests and agitations. The belief of the people over the judicial judgements and strict punishments increases, and the change in such appropriate judgements creates a sense of hopelessness. Rather than punishing the people after the crime it is better to prevent 


\section{https://doi.org/10.24113/ijellh.v7i11.10113}

the crime from being committed. The root of the problem is selfishness and indulgence in the carnal desires, which can be rooted out only through the manifestation of love from within each individual. The evolution of such a profound feeling within creates a sense of empathy over all things, and so it would be difficult to hurt other beings, for the pain generated can be felt, as there is a sense of oneness all around. This would eventually result in a peaceful world.

Influence over each individual in this world is very huge and it is the ultimate problem. Therefore to change the whole human society seems utterly non applicable. The change from within must happen in each person and such an understanding would then transfer itself to the upcoming generations, which would absolutely be peaceful and different from the present world. All the aspects regarding the incarnation of Radha and Krishna on Earth was predestined, to make the mankind realise that unconditional and unadulterated love is the purest form of devotion towards God or the macro cosmic energy that sustains life on Earth. The eternal and unconditional love does exist in the inner depths of the being, but sometimes it takes years to finally realise such a wonderful and magnificent truth which explores various dimensions of life.The love remains the same even if the people who felt it leaves the world, this is the reason that makes the love of Radha and Krishna unquestionable and eternal. Their lives through ages and even today they are being worshipped and praised for their oneness which they proved to the world as the ultimate devotion. 
https://doi.org/10.24113/ijellh.v7i11.10113

\section{Works Cited}

Desai, Kunal. My Affair with Radha. Chennai: Notionpress, 2017.

https://www.speakingtree.in/blog/universal-oneness

https://www.lovepanky.com/love-couch/romantic-love/does-eternal-love-exist 